\title{
PENGARUH VARIASI TEKANAN UDARA PADA PEMOTONGAN PLAT BAJA ST 37 MENGGUNAKAN CNC PLASMA CUTTING TERHADAP STRUKTUR MIKRO, KERFDAN KEKERASAN
}

\author{
Dedy Rizkiawan ${ }^{1}$ dan Wirawan Sumbodo ${ }^{2}$ \\ 1)Pendidikan Teknik Mesin, Jurusan Teknik Mesin, Fakultas Teknik, \\ Universitas Negeri Semarang \\ 2)Teknik Mesin, Jurusan Teknik Mesin, Fakultas Teknik, \\ Universitas Negeri Semarang \\ dedyrizkiawan14@gmail.com
}

\begin{abstract}
ABSTRAK: Penelitian ini bertujuan untuk mengetahui seberapa besar pengaruh variasi tekanan udara terhadap struktur mikro, kerf dan kekerasan pada pemotongan plat baja ST 37. Tekanan udara yang digunakan adalah $0.3 \mathrm{MPa}, 0.5 \mathrm{MPa}$ dan 0.8 $\mathrm{MPa}$. Untuk parameter yang lainnya tetap konstan yaitu kuat arus $20 \mathrm{~A}$, tinggi torch 0.1 $\mathrm{mm}$ dan feed rate $400 \mathrm{~mm} / \mathrm{s}$. Penelitian ini termasuk jenis penelitian kuantitatif dan menggunakan metode eksperimen. Untuk teknik pengumpulan data menggunakan metode observasi dan teknik analisis data menggunakan teknik analisis statistik deskriptif. Hasil penelitian pada struktur mikro didapatkann hasil yang terbaik yaitu pada tekanan udara $0.8 \mathrm{MPa}$, karena susunan struktur mikro yang dominan baik yang ditunjukan dengan rapat nya susunan antar fasa, pengambilan foto struktur mikro menggunakan mikroskop optik dengam pembesaran 200x. Kemudian untuk hasil penelitian pengukuran lebar kerf terbaik didapatkan pada tekanan udara 0.3 MPa yaitu sebesar $1.2 \mathrm{~mm}$, pengukuran lebar kerf menggunakan taper gauge. Pengujian kekerasan menggunakan uji Vickers dengan pembebanan $300 \mathrm{kgf}$ selama 10 detik
\end{abstract}

Kata kunci: tekanan udara, Strukturmikro, kerf, dan kekerasan

\section{PENDAHULUAN}

Seiring dengan perkembangan dunia industri yang semakin maju, mendorong para pelaku dunia industri untuk meningkatkan kebutuhan penggunaan alat yang lebih efektif dan efisien. Alat yang semakin canggih akan mendorong para pelaku industri untuk mendapatkan hasil yang maksimal. Plasma cutting merupakan salah satu alat yang akan mendorong para pelaku industri untuk mendapatkan hasil yang maksimal. Pemotongan plasma merupakan proses yang digunakan untuk memotong logam dengan menggunakan plasma. Dalam proses tersebut udara terkompresi dihembuskan dengan kecepatan tinggi dari nosel dan pada saat yang bersamaan listrik busur terbentuk melalui gas dari nosel ke permukaan yang telah dipotong dan mengubah sebagian gas tersebut menjadi plasma. Dengan menggunakan plasma, metode pemotongan menjadi sangat efisien dan menawarkan keuntungan besar dalam hal kecepatan potong dan biaya awal jika dibandingkan dengan oxy-fuel cutting dan water jet cutting (Pawar dan Inamdar, 2017:75). Seiring berkembangnya teknologi Mesin Plasma cutting yang semula digerakkan 
secara manual dapat dimodifikasi agar pergerkannya lebih stabil dan konstan, yaitu dengan menggunakan sistem CNC. Prinsip kerja CNC adalah membaca koordinat jarak suatu objek 2D atau 3D menjadi perintah G-Code dengan bantuan computer, dimana perintah tersebut akan menggerakkan motor sehingga dapat bergerak sesuai dengan koordinat objek tersebut (Amri dan Sumbodo.,2018:111). Plasma cutting non-conventional sudah menjadi garis kehidupan dalam dunia industri, tentunya akan sangat membantu untuk mendapatkan hasil akhir yang maksimal terutama dalam akurasi pemotongan. Para pelaku industri menuntut agar alat yang digunakan harus membantu dalam pekerjaannya.

Dalam proses pemotongan plat, kepresisian sangat dibutuhkan agar nantinya tidak menimbulkan kerf yang terlalu lebar dan kepresisian juga akan tercapai. Yang dimaksud kerf adalah celah pemotongan yang timbul akibat adanya pemotongan pada bahan material, kerf bervariasi ukurannya bergantung faktor yang mempengaruhi. Untuk mendapatkan kerf yang presisi tersebut ada beberapa faktor yang harus terpenuhi diantaranya adalah kuat arus, tekanan udara, tinggi torch, kecepatan potong (Hamid, 2018:15).

\section{METODE}

Penelitian ini menggunakan metode eksperimen. Spesimen dibuat dari plat baja ST 37 yang berbentuk persegi panjang, berukuran panjang $300 \mathrm{~mm}$ lebar $150 \mathrm{~mm}$ dan tebal $1.3 \mathrm{~mm}$, dimana spesimen ini nantinya digunakan untuk pengukuran lebar kerf. Kemudian untuk pengujian foto struktur mikro dan kekerasan menggunakan spesimen dengan ukuran panjang $100 \mathrm{~mm}$, lebar $30 \mathrm{~mm}$ dan tebal $1.3 \mathrm{~mm}$. Spesimen berjumlah 6 dimana 3 spesimen digunakan untuk pengukuran lebar kerf dan 3 spesimen digunakan untuk pengujian struktur mikro dan kekerasan.
Spesimen dilakukan pembersihan dari kotoran-kotoran dan juga karat dengan menggunakan kikir dan ampelas.

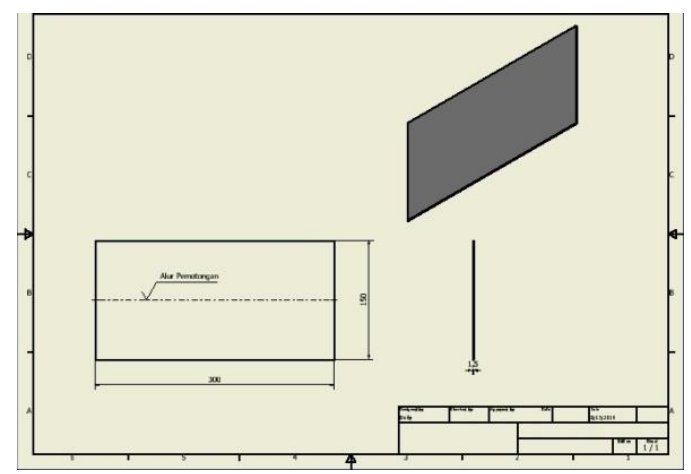

Gambar 1. Spesimen uji struktur mikro dan uji kekerasan

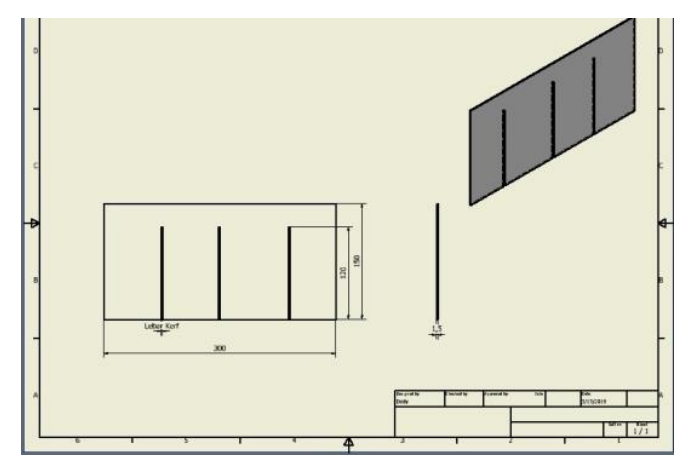

Gambar 2. Spesimen pengukuran lebar kerf

a. Proses pemotongan sampai putus

Untuk pemotongan ini nantinya akan digunakan sebagai spesimen yang di uji struktur mikro dan kekerasan. Benda uji yang berjumlah 3 spesimen dilakukan proses pemotongan dengan variasi tekanan udara $0.3 \mathrm{MPa}, 0.5 \mathrm{MPa}$ dan 0.8 $\mathrm{MPa}$. kemudian potong ke-3 spesimen tersebut secara bergantian dan dengan variasi tekanan udara yang telah ditentukan.

b. Proses separuh pemotongan

Untuk proses pemotongan ini nantinya akan digunakan sebagai spesimen yang diukur lebar kerfnya. Benda uji yang berjumlah 3 spesimen dilakukan proses pemotongan, namun tidak sampai putus, karena pada spesimen ini 
akan diukur pada lebar kerf nya. Untuk varisasi tekanan udara sama, yaitu 0.3 MPa, 0.5 MPa, dan 0.8 $\mathrm{MPa}$. Benda kerja di potong secara bergantian.

Data penelitian diambil dari masingmasing spesimen yang sudah diuji yang kemudian dianalisa. Teknik anallisis data yang digunakan pada penelitian ini adalah dengan menggunakan analisis statistik deskriptif. Statistik deskriptif yaitu statistik yang digunakan untuk menganalisis data dengan cara mendeskripsikan atau menggambarkan data yang telah terkumpul sebagaimana adanya tanpa bermaksud untuk umum atau generalisasi (Sugiyono, 2009 :147).

\section{HASIL DAN PEMBAHASAN}

1. Pengamatan struktur mikro Menurut Lely Susita R.M., dkk (1996) struktur mikro adalah struktur yang hanya bisa diamati melalui mikroskop baik itu mikroskop optik maupun mikroskop elektron.

Pengujian struktur mikro bertujuan untuk mengetahui hasil foto mikro pada spesimen uji dengan variasi tekanan udara 0.3 MPa, 0.5 MPa, dan 0.8 MPa. Pengujian struktur mikro raw material dan material yang sudah melalui proses pemotongan menggunakan plasma cutting dilakukan setelah proses pengamplasan, pemolesan dan pengetsaan dengan menggunakan $\mathrm{HNO}_{3}$ dan alkohol, perbandingannya adalah 1:4. Perbesaran 200x pada spesimen, 10 strip yang terlihat pada foto mikro, hal tersebut menunjukkan bahwa 10 strip setara dengan 50 mikrometer.

\section{a. Pengamatan struktur mikro raw material}

Penelitian ini menghasilkan data-data yang berupa angka dalam tabel dan grafik yang meliputi hasil uji komposisi, pengamatan struktur mikro, pengujian lebar kerf dan pengujian kekerasan pada material baja ST 37. Dimana data yang diambil adalah data yang terbaik dan nantinya akan dijadikan sebagai parameter pada saat melakukan pemotongan plat baja ST 37 dengan tebal $1.3 \mathrm{~mm}$.

Penelitian dilakukan untuk memperoleh data kekasaran permukaan dari masing masing spesimen yang telah diberi perlakuan berbeda. Pengambilan data dilakukan dengan cara pengujian pada permukaan spesimen menggunakan surface tester (Surfcorder SE-1700). Pengambilan data dan pengujian dilakukan di Laboratorium Bahan Teknik Universitas Gadjah Mada. Proses pengujiannya dilakukan dengan cara mengambil 1 titik uji untuk memperoleh data pengujian kekasaran dari masingmasing spesimen yang berjumlah 3 untuk variasi yang sama, kemudian data yang diperoleh diambil rata-ratanya untuk menghasilkan perbandingan ratarata kekasaran permukaan (Ra) dari seluruh permukaan spesimen yang dilakukan pengujian

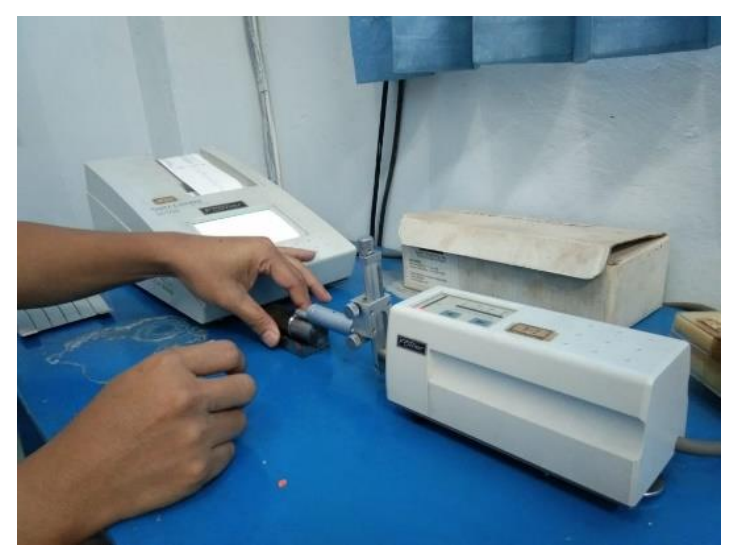

Gambar 3. Proses pengujian kekasaran

Proses pengerjaan dilakukan dengan cara mengambil 1 titik uji untuk memperoleh data pengujian kekasaran dari 27 spesimen, kemudian data yang diperoleh diambil rata-ratanya untuk menghasilkan perbandingan rata-rata kekasaran permukaan (Ra) dari seluruh permukaan spesimen yang dilakukan pengujian.

Tabel 1. Hasil pengujian kekasaran 


\begin{tabular}{|c|c|c|c|c|c|}
\hline \multirow[b]{2}{*}{$\begin{array}{l}\text { Feed } \\
\text { Rate }\end{array}$} & \multirow[b]{2}{*}{$\begin{array}{c}\text { Dep } \\
\text { th of } \\
\text { Cut }\end{array}$} & \multicolumn{4}{|c|}{ Nilai kekasaran ( $\mu \mathrm{m})$} \\
\hline & & $\begin{array}{l}\text { Spe } \\
\text { S. } 1\end{array}$ & $\begin{array}{l}\text { Spe } \\
\text { s. } 2\end{array}$ & $\begin{array}{l}\text { Spe } \\
\text { S. } 3\end{array}$ & $\begin{array}{l}\text { Rat } \\
\text { a- } \\
\text { rata }\end{array}$ \\
\hline \multirow{5}{*}{$\begin{array}{c}0,2 \\
\mathrm{~mm} / \mathrm{r} \\
\mathrm{ev}\end{array}$} & $\begin{array}{c}0,2 \\
\mathrm{~mm}\end{array}$ & $\begin{array}{l}4,7 \\
81 \\
\end{array}$ & $\begin{array}{c}4,8 \\
62 \\
\end{array}$ & $\begin{array}{c}4,9 \\
67 \\
\end{array}$ & $\begin{array}{l}4,8 \\
70 \\
\end{array}$ \\
\hline & $\begin{array}{l}0,3 \\
\mathrm{~mm}\end{array}$ & $\begin{array}{l}3,5 \\
85\end{array}$ & $\begin{array}{l}3,5 \\
99\end{array}$ & $\begin{array}{c}3,8 \\
08\end{array}$ & $\begin{array}{l}3,6 \\
44 \\
\end{array}$ \\
\hline & $\begin{array}{l}1,3 \\
\mathrm{~mm}\end{array}$ & $\begin{array}{l}1,9 \\
12 \\
\end{array}$ & $\begin{array}{r}2,1 \\
04 \\
\end{array}$ & $\begin{array}{l}2,1 \\
71 \\
\end{array}$ & $\begin{array}{c}2,0 \\
62 \\
\end{array}$ \\
\hline & $\begin{array}{l}2,3 \\
\mathrm{~mm}\end{array}$ & $\begin{array}{r}2,1 \\
49 \\
\end{array}$ & $\begin{array}{l}2,4 \\
72 \\
\end{array}$ & $\begin{array}{l}2,2 \\
22 \\
\end{array}$ & $\begin{array}{c}2,2 \\
81 \\
\end{array}$ \\
\hline & $\begin{array}{l}2,5 \\
\mathrm{~mm}\end{array}$ & $\begin{array}{c}2,2 \\
71\end{array}$ & $\begin{array}{c}2,3 \\
26\end{array}$ & $\begin{array}{c}2,0 \\
62\end{array}$ & $\begin{array}{c}2,2 \\
20\end{array}$ \\
\hline $\begin{array}{c}0,05 \\
\mathrm{~mm} / \mathrm{r} \\
\mathrm{ev}\end{array}$ & \multirow{5}{*}{$\begin{array}{l}1,3 \\
\mathrm{~mm}\end{array}$} & $\begin{array}{l}1,5 \\
14\end{array}$ & $\begin{array}{c}1,2 \\
10\end{array}$ & $\begin{array}{l}1,6 \\
64\end{array}$ & $\begin{array}{l}1,4 \\
63\end{array}$ \\
\hline $\begin{array}{c}0,1 \\
\mathrm{~mm} / \mathrm{r} \\
\mathrm{ev}\end{array}$ & & $\begin{array}{l}1,4 \\
46\end{array}$ & $\begin{array}{l}1,6 \\
68\end{array}$ & $\begin{array}{l}1,3 \\
07\end{array}$ & $\begin{array}{l}1,4 \\
80\end{array}$ \\
\hline $\begin{array}{c}0,2 \\
\mathrm{~mm} / \mathrm{r} \\
\mathrm{ev}\end{array}$ & & $\begin{array}{l}1,9 \\
12\end{array}$ & $\begin{array}{r}2,1 \\
04\end{array}$ & $\begin{array}{l}2,1 \\
71\end{array}$ & $\begin{array}{l}2,0 \\
62\end{array}$ \\
\hline $\begin{array}{c}0,4 \\
\mathrm{~mm} / \mathrm{r} \\
\mathrm{ev}\end{array}$ & & $\begin{array}{l}2,3 \\
73 \\
\end{array}$ & $\begin{array}{c}2,4 \\
60 \\
\end{array}$ & $\begin{array}{c}2,2 \\
37 \\
\end{array}$ & $\begin{array}{l}2,3 \\
57 \\
\end{array}$ \\
\hline $\begin{array}{c}0,5 \\
\mathrm{~mm} / \mathrm{r} \\
\mathrm{ev}\end{array}$ & & $\begin{array}{l}2,7 \\
45 \\
\end{array}$ & $\begin{array}{c}2,9 \\
13 \\
\end{array}$ & $\begin{array}{r}2,7 \\
49 \\
\end{array}$ & $\begin{array}{c}2,8 \\
02 \\
\end{array}$ \\
\hline
\end{tabular}

Nilai kekasaran kelompok pertama dengan variable kontrol feeding $0,2 \mathrm{~mm}$ /rev dengan variasi kedalaman pemakanan sebesar $0,2 \mathrm{~mm}$ diperoleh nilai kekasaran sebesar 4,870 $\mu \mathrm{m}$, kedalaman pemakanan sebesar $0,3 \mathrm{~mm}$ diperoleh nilai kekasaran sebesar 3,664 $\mu \mathrm{m}$, kedalaman pemakanan sebesar 2,3 $\mathrm{mm}$ diperoleh nilai kekasaran sebesar 2,281 $\mu \mathrm{m}$, dan pada kedalaman pemakanan sebesar $2,5 \mathrm{~mm}$ diperoleh nilai kekasaran sebesar 2,220 $\mu \mathrm{m}$. Pada variable kontrol laju pemakanan yang di variasikan dengan kedalaman pemakanan dapat disimpulkan bahwa semakin tinggi kedalaman pemakanan dengan laju pemakanan 0,02 $\mathrm{mm} / \mathrm{rev}$ maka hasil dari kekasaran benda yang didapat akan semakin rendah.

Nilai kekasaran kelompok kedua dengan variabel kontrol kedalaman pemakanan 1,3 $\mathrm{mm}$ dengan variasi laju pemakanan sebesar 0,05 $\mathrm{mm} / \mathrm{rev}$ diperoleh nilai kekasaran sebesar 1,463 $\mu \mathrm{m}$, kedalaman pemakanan sebesar 0,1 $\mathrm{mm} / \mathrm{rev}$ diperoleh nilai kekasaran sebesar 1,480 $\mu \mathrm{m}$, kedalaman pemakanan sebesar 0,4 $\mathrm{mm} / \mathrm{rev}$ diperoleh nilai kekasaran sebesar 2,357 $\mu \mathrm{m}$, dan pada kedalaman pemakanan sebesar 0,5 $\mathrm{mm} / \mathrm{rev}$ diperoleh nilai kekasaran sebesar 2,802 $\mu \mathrm{m}$. Pada variable kontrol kedalaman pemakanan yang di variaasikan dengan laju pemakanan dapat disimpulkan bahwa semakin kecil laju pemakanan dengan kedalaman pemakanan 1,3 $\mathrm{mm}$ maka hasil dari kekasaran benda yang didapat akan semakin rendah.

Pada penelitian ini menunjukkan bahwa kedalaman potong dan kecepatan pemakanan mempengaruhi nilai tingkat kekasaran permukaan suatu benda. Nilai kekasaran rata-rata permukaan suatu benda (Ra) pada masing-masing spesimen menunjukkan tingkat nilai kekasaran yang berbeda. Untuk ini dibuat 2 variabel sebagai kontrol dengan penggunaan laju pemakanan 0,2 $\mathrm{mm} / \mathrm{rev}$ dan kedalaman pemakanan 1,3 $\mathrm{mm}$. 


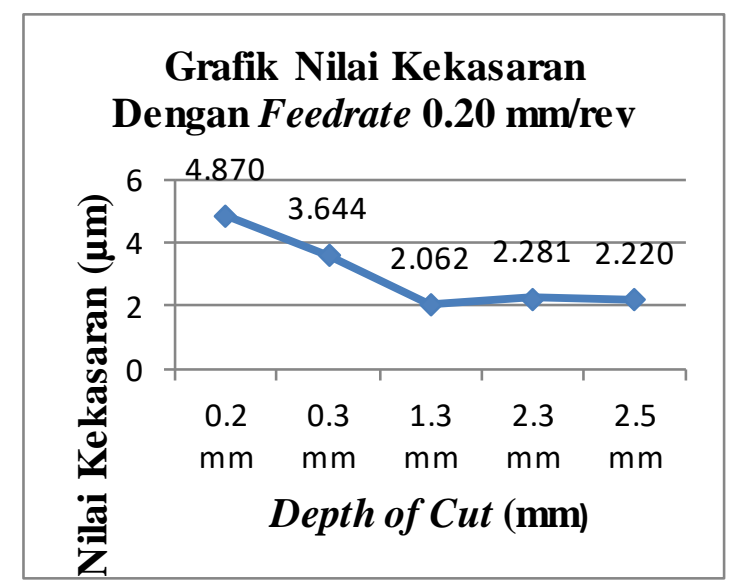

Gambar 3. Grafik nilai kekasaran dengan feedrate sebesar $0.20 \mathrm{~mm} / \mathrm{rev}$

Pada penggunaan laju pemakanan 0,2 $\mathrm{mm} / \mathrm{rev}$ nilai kekasaran permukaan paling rendah didapatkan oleh pembubutan dengan memvariasikan kedalaman pemakanan pada $2,5 \mathrm{~mm}$ yaitu sebesar 2,220 $\mu \mathrm{m}$, sedangkan nilai kekasaran permukaan paling tinggi didapatkan oleh pembubutan dengan memvariasikan kedalaman pemakanan pada $0,2 \mathrm{~mm}$ yaitu sebesar $4,870 \mu \mathrm{m}$.

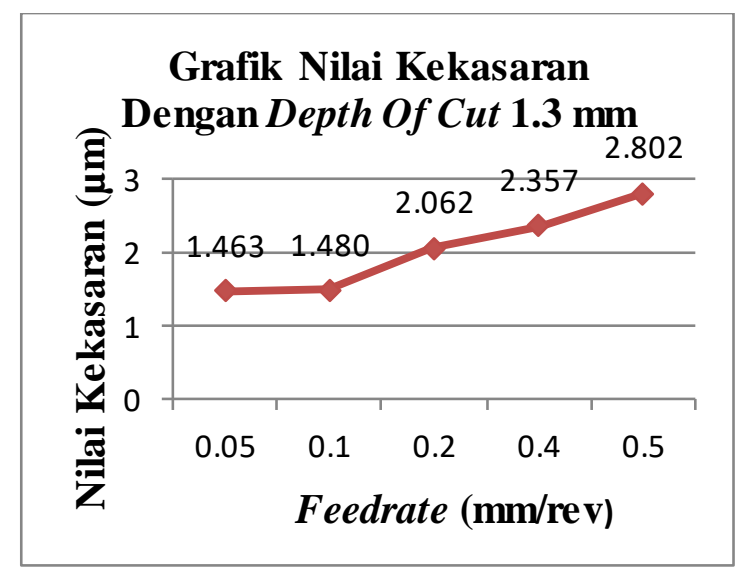

Gambar 4. Grafik nilai kekasaran dengan Depth of Cut sebesar 1,3mm

Pada penggunaan kedalaman pemakanan 1,3 $\mathrm{mm}$ nilai kekasaran permukaan paling rendah didapatkan oleh pembubutan dengan memvariasikan laju pemakanan pada $0,05 \mathrm{~mm} / \mathrm{rev}$ yaitu sebesar 1,463 $\mu \mathrm{m}$, sedangkan nilai kekasaran permukaan paling tinggi didapatkan oleh pembubutan dengan memvariasikan laju pemakanan pada $0,5 \mathrm{~mm} / \mathrm{rev}$ yaitu sebesar 2,802 $\mu \mathrm{m}$.

\section{Grafik Kekasaran Laju Pemakanan dan Kedalaman Pemakanan}

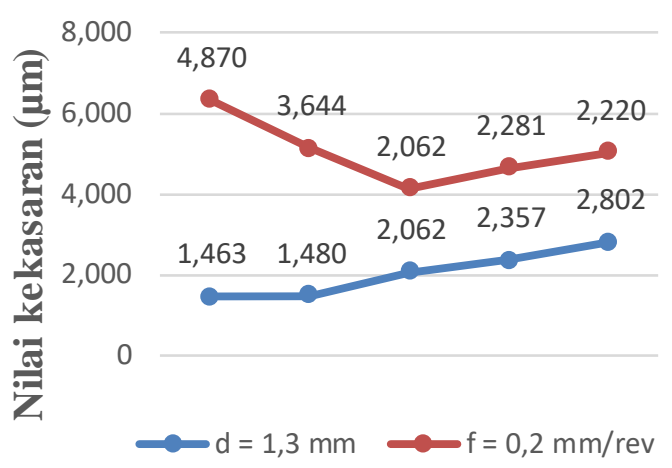

Gambar 5. Hubungan pengaruh laju pemakanan dan kedalaman terhadap tingkat kekasaran permukaan

Garis warna merupakan kondisi dari hasil nilai kekasaran permukaan dari pengaruh laju pemakanan dan kedalaman pemakanan dimana nilai kekasaran permukaan hasil pembubutan dipengaruhi oleh laju pemakanan dan kedalaman pemakanan, hasil dari memvariasikan laju pemakanan sebesar 0,2 $\mathrm{mm} / \mathrm{rev}$ dengan kedalaman pemakanan diperoleh hasil kekasaran paling rendah 2,220 $\mu \mathrm{m}$., kemudian hasil terbaik dari memvariasikan kedalaman pemakanan sebesar 1,3 $\mathrm{mm}$ dengan laju pemakanan diperoleh hasil kekasaran $1,463 \mu \mathrm{m}$, dan hasil kekasaran 2,062 $\mu \mathrm{m}$ adalah sebagai kontrol dari memvariasikan laju pemakanan 0,2 $\mathrm{mm} / \mathrm{rev}$ dengan kedalaman pemakanan 1,3 $\mathrm{mm}$.

Tabel 2. Kategori nilai pengujian kekasaran

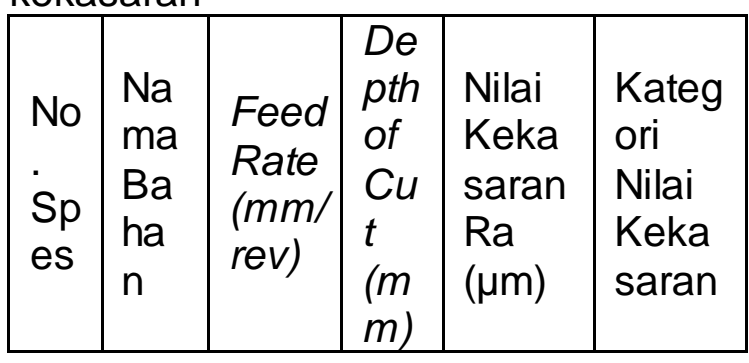




\begin{tabular}{|c|c|c|c|c|c|}
\hline 1 & $\begin{array}{l}\text { Baj } \\
\text { a } \\
\text { ST } \\
60\end{array}$ & 0,20 & 1,3 & 2,062 & $\begin{array}{l}\text { N7 } \\
\text { N8 }\end{array}$ \\
\hline 2 & $\begin{array}{l}\text { Baj } \\
\text { a } \\
\text { ST } \\
60\end{array}$ & 0,20 & 0,2 & 4,870 & $\begin{array}{l}\text { N8 } \\
\text { N9 }\end{array}$ \\
\hline 3 & $\begin{array}{l}\text { Baj } \\
\text { a } \\
\text { ST } \\
60\end{array}$ & 0,20 & 0,3 & 3,644 & $\begin{array}{l}\text { N8 } \\
\text { N9 }\end{array}$ \\
\hline 4 & $\begin{array}{l}\text { Baj } \\
\text { a } \\
\text { ST } \\
60\end{array}$ & 0,20 & 2,3 & 2,281 & $\begin{array}{l}\text { N7 } \\
\text { N8 }\end{array}$ \\
\hline 5 & $\begin{array}{l}\text { Baj } \\
\text { a } \\
\text { ST } \\
60\end{array}$ & 0,20 & 2,5 & 2,220 & $\begin{array}{l}\text { N7 } \\
\text { N8 }\end{array}$ \\
\hline 6 & $\begin{array}{l}\text { Baj } \\
\text { a } \\
\text { ST } \\
60\end{array}$ & 0,05 & 1,3 & 1,463 & $\begin{array}{l}\text { N6 } \\
\text { N7 }\end{array}$ \\
\hline 7 & $\begin{array}{l}\text { Baj } \\
\text { a } \\
\text { ST } \\
60\end{array}$ & 0,10 & 1,3 & 1,480 & $\begin{array}{l}\text { N6 } \\
\text { N7 }\end{array}$ \\
\hline 8 & $\begin{array}{l}\text { Baj } \\
\text { a } \\
\text { ST } \\
60\end{array}$ & 0,40 & 1,3 & 2,357 & $\begin{array}{l}\text { N7 } \\
\text { N8 }\end{array}$ \\
\hline 9 & $\begin{array}{l}\text { Baj } \\
\text { a } \\
\text { ST } \\
60\end{array}$ & 0,50 & 1,3 & 2,802 & $\begin{array}{l}\text { N7 } \\
\text { N8 }\end{array}$ \\
\hline
\end{tabular}

Pada penelitian dari Hadimi (2018:27) menyatakan bahwa laju pemakanan yang semakin besar mengakibatkan kekasaran suatu benda akan menjadi besar, sebaliknya laju pemaknan yang semakin rendah akan menghasilkan kekasaran permukaan benda yang semakin rendah. Berdasarkan parameter pada proses pembubutan dalam penelitian ini menunjukan tingkat kekasaran ( $\mathrm{Ra}$ ) yang berbeda dalam tiap spesimen mengalami kenaikan nilai kekasaran $(\mathrm{Ra})$ yang signifikan, bahwa semakin gerak kecepatan pemakanan (feedrate) besar pada kedalaman potong yang tetap sebesar $1,3 \mathrm{~mm}$ menghasilkan tingkat kekasaran yang tinggi, sedangkan semakin tinggi kedalaman pemakanan (depth of cut) pada laju pemakanan yang tetap sebesar $0,2 \quad \mathrm{~mm} / \mathrm{rev}$ maka menghasilkan tingkat kekasaran yang rendah.

Pada penelitian ini nilai kekasaran (Ra) permukaan dipengaruhi kedalaman potong dan kecepatan pemakanan, sedangkan parameter pembubutan yang lain seperti putaran spindel, sudut pahat, benda kerja dan jenis pahat diasumsikan sama. Nilai kekasaran spesimen digolongkan oleh peneliti dengan menggunakan ISO 1302 dalam satuan micronmeter $(\mu \mathrm{m})$ dengan simbol yang dapat dilihat pada tabel 2.9. Hasil konversi penggolongan nilai kekasaran ditunjukan pada tabel 3.0, sehingga dapat diketahui kategori nilai kekasaran dari masing-masing spesimen.

Menurut Munadi (1988:312) tingkat kekasaran menurut proses pengerjaan pada proses pembubutan memiliki nilai kekasaran pada umumnya N5 - N12 dengan harga $0,4 \mu \mathrm{m}-50,0 \mu \mathrm{m}$. Penelitian ini memiliki nilai kekasaran pada rentang N6 - N9. Jadi nilai kekasaran yang dihasilkan pada penelitian ini berada pada batas nilai kekerasan proses pembubutan.

\section{SIMPULAN}

Berdasarkan hasil penelitian yang dilakukan pada pengaruh kedalaman pemakanan dan laju pemakanan terhadap kekasaran permukaan baja karbon ST 60 dapat disimpulkan bahwa:

1. Ada pengaruh kedalaman pemakanan terhadap tingkat kekasaran permukaan pembubutan baja karbon ST 60 dengan menggunakan laju pemakanan kontrol sebesar 0,2 
$\mathrm{mm} / \mathrm{rev}$ dimana nila kekasaran dengan kedalaman pemakanan $0,2 \mathrm{~mm}, 0,3 \mathrm{~mm}, 2,3 \mathrm{~mm}$, dan 2,5 $\mathrm{mm}$ secara berturut-turut mengalami perbedaan yang signifikan. Disimpulkan bahwa semakin tinggi kedalaman potong yang digunakan, maka menghasilkan nilai kekasaran yang rendah. Semakin tinggi kedalaman potong yang digunakan maka nilai kekasaran yang dihasilkan semakin rendah.

2. Ada pengaruh laju pemakanan terhadap tingkat kekasaran permukaan pembubutan baja karbon ST 60 dengan menggunakan kedalaman pemakanan kontrol sebesar 1,3 $\mathrm{mm}$ dimana nila kekasaran dengan kedalaman pemakanan $0,05 \mathrm{~mm} / \mathrm{rev}, 0,1 \mathrm{~mm} / \mathrm{rev}, 0,4$ $\mathrm{mm} / \mathrm{rev}$, dan $0,5 \mathrm{~mm} / \mathrm{rev}$ secara berturut-turut mengalami perbedaan yang signifikan. Disimpulkan bahwa semakin tinggi laju kedalaman yang digunakan, maka menghasilkan nilai kekasaran yang tinggi, dan sebaliknya semakin rendah laju pemakanan yang digunakan maka nilai kekasaran yang dihasilkan semakin rendah.

\section{DAFTAR PUSTAKA}

Abbas, H., Bontong, Y., Aminy, Y., Azis, N., dan Arief, S. 2013. Pengaruh Parameter Pemotongan pada Operasi Pemotongan Milling terhadap Getaran dan Tingkat Kekasaran Permukaan (SurfaceRoughness),(http://repository .unhas.ac.ida. diakses pada 20 Desember 2018).

Hadimi. 2008. Pengaruh Perubahan Kecepatan Pemakanan Terhadap Kekasaran Permukaan Pada Proses Pembubutan (11). Jurusan Teknik Mesin Politeknik Negeri Pontianak: 18 -28 .
I G. N.K. Yudhyadi., Rachmanto, T., Ramadan Adnan, A. 2016. Optimasi Parameter Permesinan Terhadap Waktu Proses Pada Pemrogaman CNC Milling Dengan Berbasis $C A D / C A M$. Jurusan Teknik Mesin Fakultas Teknik Universitas Mataram: $38-39$.

Lesmono, I., Yunus. 2013. Pengaruh Jenis Pahat, Kecepatan Spindle, Dan Kedalaman Pemakanan Terhadap Tingkat Kekasaran Dan Kekerasan Permukaan baja St 42 Pada Proses Bubut Konvensional. JTM, 1 (3).

Munadi, S., 1998. Dasar - dasar Metrologi Industri. Jakarta: Departemen Pendidikan dan Kebudayaan.

Sugiyono. 2017. metode penelitian kuantitatif, kualitatif dan r\&d. Bandung: CV. Alfabeta.

Sulthan Adib, E. S. (2015). Pengaruh Spindle Speed dan Feed Rate Terhadap Bottom Surface Roughness Pada Proses Milling CNC 4- Axis. Jurusan Teknik Mesin Fakultas Teknik Universitas Brawijaya: 1-10.

Sumbodo, Wirawan. 2008. Teknik Produksi Mesin Industri. Jilid 2. Jakarta: Direktorat Pembinaan Sekolah Menengah Kejuruan (Departemen Pendidikan Nasional).

Zubaidi, A., Darmanto, I. 2012. Analisis pengaruh kecepatan putar dan kecepatan pemakanan terhadap kekasaran permukaan material FCD 40 pada mesin bubut CNC: Universitas Wahid Hasyim Semarang. 